\title{
Ethylene-hexene copolymer derived from [t-butylfluorenylsilyl-amido] dimethyl titanium complex
}

\author{
E. Chaichana ${ }^{1}$, S. Khaubunsongserm ${ }^{2}$, P. Praserthdam ${ }^{1}$, B. Jongsomjit ${ }^{*}$ \\ ${ }^{1}$ Center of Excellence on Catalysis and Catalytic Reaction Engineering, Department of Chemical Engineering, Faculty of \\ Engineering, Chulalongkorn University, Bangkok 10330, Thailand \\ 2PTT Public Company Limited, PTT Research and Technology Institute, Wangnoi, Ayuthaya 13170, Thailand
}

Received 15 September 2009; accepted in revised form 16 November 2009

\begin{abstract}
The copolymers of ethylene and 1-hexene were prepared with half-metallocene titanium complex ( $\left[\mathrm{t}-\mathrm{BuNSiMe} \mathrm{Fl}_{2} \mathrm{Flu} \mathrm{TiMe}_{2}\right.$ ) and modified methylaluminoxane (MMAO). The initial concentrations of 1-hexene were varied to investigate how the different amounts of comonomer affect on the catalytic activity of copolymerization system and microstructure of the copolymers. It has been found that this catalytic system was not active for hexene polymerization, however, it can be active when ethylene was introduced to perform ethylene-hexene copolymerization. As comonomer, 1-hexene provides positive comonomer effect on the system although very high concentration of 1-hexene was introduced. However, the microstructures of the obtained copolymers, which were examined by ${ }^{13} \mathrm{C}-\mathrm{NMR}$ need to be improved because with highly alternating sequence distribution of comonomer causing them losing some essential specific thermal properties.
\end{abstract}

Keywords: polymer synthesis, molecular engineering, metallocene, copolymer, LLDPE

\section{Introduction}

It is generally presumed that crystallinity of polymer plays an important role in determining the polymer properties, such as mechanical and thermal properties $[1,2]$. We have known that, in synthesis of linear low-density polyethylene (LLDPE) by copolymerization of ethylene with $\alpha$-olefins, the crystallinity depends mainly on the amount of $\alpha$-olefin (comonomer) content in copolymer [3]. So, if the comonomer content can be controlled, properties of copolymer can be also altered. Appropriate crystallinity or comonomer content is varied depending on the application of polymer. The high comonomer content of copolymer has been commercially produced, named plastomers [1]. The advantages of plastomers are low density, high elongation, and low haze in film form. In order to obtain the plastomer derived from the metallocene catalysts, the open structure of metallocene catalyst is crucial. Half-metallocenes and/or constrained geometry catalysts (CGCs) are subset of general metallocene catalyst, which pose the open structure because they have just one cyclopentadienyl ring (or their family, such as, indenyl or fluorenyl rings) bonded with the group IV transition metal leaving the opposite side of that ring large enough space for comonomer incorporation with less hindrance [4]. Therefore, plastomers or LLDPE with high comonomer content can be obtained with this type of catalyst.

As mentioned, comonomer contents are sensitive to many factors, such as the structure of catalyst, type of catalyst activators and the initial concentration of comonomer in the system. When considering the initial concentration, it has been found that the initial comonomer concentration not only affects

*Corresponding author, e-mail: bunjerd.j@chula.ac.th

(c) BME-PT 
directly on the comonomer contents, but it also affects on the catalytic activity of system [5, 6]. Therefore, in this present study the effect of the initial comonomer concentration in ethylene-1-hexene copolymerization with half-metallocene is investigated to determine both the catalytic performance and the specification of the obtained copolymers.

\section{Experimental}

\subsection{Materials}

All operations were manipulated under an argon atmosphere using glove box and/or standard Schlenk techniques. The $\left[\mathrm{t}-\mathrm{BuNSiMe} \mathrm{Flu}_{2} \mathrm{TiMe}_{2}\right.$ (Ti-complex) was synthesized according to the procedure described by Hagihara et al. [7]. Ethylene (polymerization grade) was obtained from the National Petrochemical Co. Ltd., Thailand. 1-Hexene $(\geq 97 \%)$ was purchased from Aldrich Chemical Company, Thailand and further purified by distilling over $\mathrm{CaH}_{2}$ for $6 \mathrm{~h}$. Modified methyl aluminoxane, MMAO [(Me-Al-O- $\left.)_{m}-(\mathrm{i}-\mathrm{Bu}-\mathrm{Al}-\mathrm{O}-)_{n}\right]$ having $1.86 \mathrm{M}$ in toluene, was donated by Tosoh Akzo, Japan. Toluene (commercial grade) was donated by the Exxon Chemical, Thailand Co. Ltd. It was dried over dehydrated $\mathrm{CaCl}_{2}$ and distilled over sodium/ benzophenone.

\subsection{Polymerization procedure}

Ethylene/1-hexene copolymerization reaction was carried out in a $100 \mathrm{ml}$ semibatch stainless steel autoclave reactor equipped with a magnetic stirrer. At first, the desired amounts of MMAO and the toluene were introduced into the reactor. The titanium complex in toluene $\left(10 \mu \mathrm{mol} \cdot \mathrm{ml}^{-1}\right)$ was put into the reactor to make the $[\mathrm{Al}]_{\mathrm{MMAO}} /[\mathrm{Ti}]_{\text {cat }}=400$. Then, the reactor was immersed in liquid nitrogen. 1-hexene was added into the frozen reactor (to stop or prevent possible polymerization of 1-hexene). The reactor was heated up to the polymerization temperature at $343 \mathrm{~K}$. The polymerization was started by feeding ethylene ( 0.018 moles) into the reactor. The ethylene pressure and reactor temperature were kept constant during the polymerization (pressure in reactor $=349 \mathrm{kPa}(50 \mathrm{psi})$ ). Due to the fixed ethylene consumption (at 0.018 moles), the polymerization time was defined as the time that all ethylene gas was totally consumed (the equivalent pressure drop of $42 \mathrm{kPa}$ (6 $\mathrm{psi}$ ) was observed). The polymerization time was recorded to calculate the activity. The reaction was terminated by adding acidic methanol and the material was stirred for $30 \mathrm{~min}$. After filtration, the copolymer obtained was washed with methanol and dried at room temperature.

\section{3. ${ }^{13} \mathrm{C}$-NMR spectroscopy}

${ }^{13} \mathrm{C}$-NMR spectroscopy was used to determine the $\alpha$-olefin incorporation and copolymer microstructure. Chemical shifts were referenced internally to the $\mathrm{CDCl}_{3}$ and calculated according to the method described by Randall [8]. Each sample solution was prepared by dissolving $50 \mathrm{mg}$ of copolymer in 1,2,4-trichlorobenzene and $\mathrm{CDCl}_{3} \cdot{ }^{13} \mathrm{C}$-NMR spectra were taken at $333 \mathrm{~K}$ using a BRUKER AVANCE II 400 operating at $100 \mathrm{MHz}$ with an acquisition time of $1.5 \mathrm{~s}$ and a delay time of $4 \mathrm{~s}$.

\subsection{Differential scanning calorimetry}

The melting temperature of ethylene/1-octene copolymer products was determined with a PerkinElmer diamond DSC. The analyses were performed at the heating rate of $20^{\circ} \mathrm{C} / \mathrm{min}$ in the temperature range of $50-150^{\circ} \mathrm{C}$. The heating cycle was run twice. In the first scan, samples were heated, and then cooled to room temperature. In the second scan, samples were reheated at the same rate, but only the results of the second scan were reported because the first scan was influenced by the mechanical and thermal history of samples.

\section{Results and discussion}

\subsection{Reactivity of (co)monomer to catalyst}

The catalytic activities based on polymer product are shown in Table 1. It can be seen that there is no catalytic activity for system conducted with only 1-hexene as monomer (entry 1). The opposite occurred on entry 2 for the system that used only ethylene as monomer. It suggests that this half-metallocene catalyst ([t-BuNSiMe $\mathrm{Flu}_{2} \mathrm{TiMe}_{2}$ ) is active for ethylene polymerization, but not for 1-hexene polymerization. This result agreed with the finding of Intaragamjon et al. [9], who reported that this catalyst cannot proceed 1-hexene polymerization under the specified condition. It has been known that ethylene is the most reactive olefin 
Table 1. Activities of system with various monomer concentrations

\begin{tabular}{|c|c|c|c|c|c|}
\hline Entry & $\begin{array}{c}\text { Ethylene }^{\mathbf{a}} \\
{[\mathbf{m o l} / \mathbf{l}]}\end{array}$ & $\begin{array}{c}\text { 1-Hexene } \\
{[\mathbf{m o l} / \mathbf{l}]}\end{array}$ & $\begin{array}{c}\text { Time } \\
{[\mathbf{s}]}\end{array}$ & $\begin{array}{c}\text { Weight } \\
{[\mathbf{g}]}\end{array}$ & $\begin{array}{c}\text { Activity } \\
(\mathbf{k g} \text { polymer/mol Ti .h) }\end{array}$ \\
\hline 1 & 0.0 & 0.6 & 475 & - & - \\
\hline 2 & 0.6 & 0.0 & 475 & 0.2468 & 187 \\
\hline 3 & 0.6 & 0.3 & 500 & 1.0596 & 763 \\
\hline 4 & 0.6 & 0.6 & 248 & 1.4030 & 2037 \\
\hline 5 & 0.6 & 1.2 & 326 & 1.9241 & 2125 \\
\hline
\end{tabular}

aEthylene addition into the system

bCopolymerization condition: $\mathrm{Ti}=10 \mu \mathrm{mol}, \mathrm{Al} / \mathrm{Ti}=400$, temperature $=343 \mathrm{~K}, 349 \mathrm{kPa}(50 \mathrm{psi})$ of ethylene pressure was applied

[10], so it can react with itself for polymerization in the absence of any comonomer. Although 1-hexene was not reactive in its homopolymerization, it can be reacted in the system of copolymerization with ethylene (entry 3-5). Thus, this should be clarified in this finding that why 1-hexene was not active unless ethylene was introduced together in the system, even with the small amount of ethylene as seen for entry 5.

The mechanism of polymerization by metallocene catalyst system is reviewed here to explain the result. There are three main steps for completing the copolymerization (excluding chain transfer step), as shown in Figure 1 [10]. The first step is the 'activation' of metallocene catalyst typically achieving via contact with an appropriate cocatalyst species (MMAO in this case). The second is the 'initiation' of the polymerization occurring as a result of the displacement of the anion and coordination of the monomer in the primary complex. In our study, this step seems to be a problem for obtaining the 1-hexene polymerization, since the ion-pairs still stay in their coordinated tightly. Therefore, only the strong reactive monomer like ethylene is able to insert in this coordination, and consequently displace the anion and make coordination with catalyst active site. This step can generate an available coordination site on the metal center, which provides high enough space for a large molecule, such as 1-hexene to coordinate with it in the next step. As the result, the final step that is the 'propagation' step will be the open competition between ethylene monomer and 1-hexene comonemer for insertion into the growing chain of polymer.

As describe above, for this catalytic system, if ethylene was not introduced into the system first, 1-hexene would not be reactive for this half-metallocene catalyst even open structure. However, in many cases, 1-hexene can perform polymerization by itself with some metallocenes such as $\mathrm{iPr}(\mathrm{Cp})(\mathrm{Flu}) \mathrm{ZrCl}_{2}$ and $\mathrm{En}(\mathrm{Ind})_{2} \mathrm{ZrCl}_{2}$ [11] indicating that reactivities of $\alpha$-olefin also depend on the catalyst structure [12].

\subsection{Effect of the amount of 1 -hexene on catalytic activity}

In entry 3-5, introducing of 1-hexene into copolymerization enhanced catalytic activity higher than

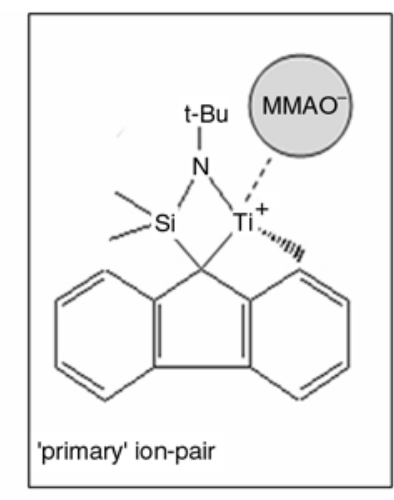

Activation

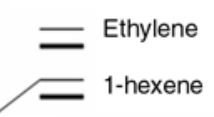

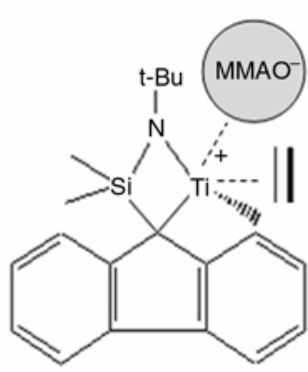

Initiator

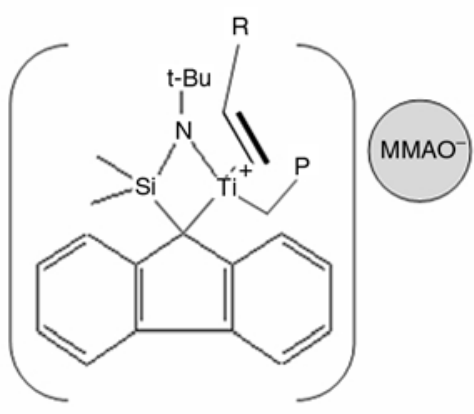

Propagation

Figure 1. Schematic representation of copolymerization mechanism 


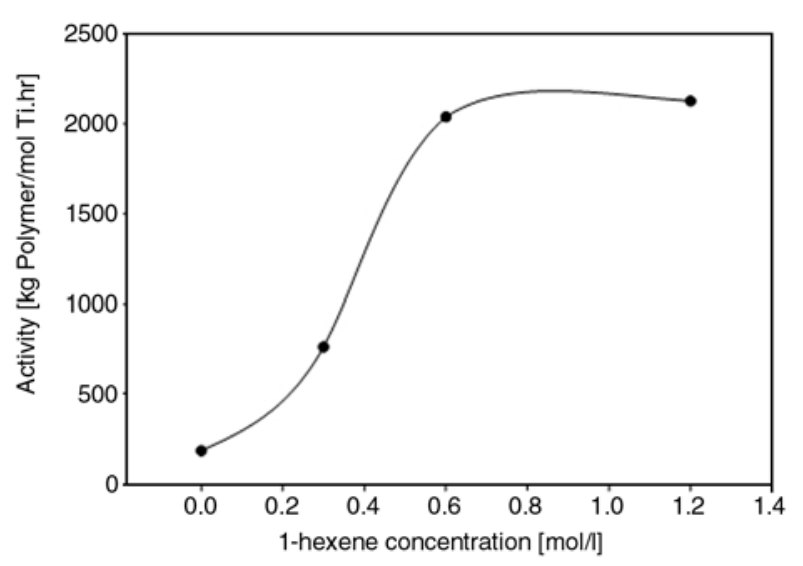

Figure 2. Activity profile with various 1-hexene concentrations

that of system without 1-hexene (entry 2). When the amounts of 1-hexene were increased, the catalytic activities were also increased. They increased pronouncedly when the amount of 1-hexene was raised from 0.3 to $0.6 \mathrm{~mol} / \mathrm{l}$. However, they gradually increased when the amount of 1-hexene was raised two times again from 0.6 to $1.2 \mathrm{~mol} / \mathrm{l}$. A comparison of activities is also shown in Figure 2. It can be explained that the first range of increasing is because of comonomer effect in copolymerization behavior [13]. The chain structure of 1-hexene can increase the gap between the cationic active species and counter anion more separately in propagation step (Figure 1). Then, the propagation rate of polymerization can be raised leading to enhancing the activity of copolymerization. However, at $1.2 \mathrm{~mol} / \mathrm{l}$ of 1-hexene concentration (entry 5), the anticipated activity can not be attained. This is because high excess of 1-hexene obstructed active sites of catalyst from reacting with ethylene monomer, and consequently reduce rate of ethylene insertion into the chain of growing polymer. The explanation can be supported by polymerization time of entry 5, which was longer than that of entry 4 . The longer polymerization time suggests that, in entry 5, the rate of ethylene consumption for polymerization was slower than that of entry 4.
Although the rate of ethylene consumption in entry 4 was faster, activity or productivity of entry 5 was higher. This is because initial concentration of 1-hexene of entry 5 was higher then it can produce more product than entry $\mathbf{4}$ did resulting in high catalytic activity for the system.

\subsection{Effect of the amount of 1 -hexene on microstructure of copolymers}

As seen in Table 2, the comonomer incorporations apparently increased with increasing the amount of 1-hexene in copolymerization. In this copolymerization process, which fixed the amount of ethylene addition and kept ethylene pressure constant during copolymerization, the incorporation of 1-hexene can be increased by two primary reasons. One is that enhancing the reactivity of 1-hexene or two, diminishing the reactivity of ethylene. It can be seen from Table 2 that reactivities of ethylene decreased dramatically with increasing the concentration of 1-hexene in the system while reactivities of 1-hexene just slightly increased. So, it can be concluded that the initial concentrations of 1-hexene in the system have more effect on the reactivity of ethylene than itself. The increase of 1-hexene reactivity enables it to still incorporate continuously into the growing chain even at high concentration. The open structure of half-metallocene catalyst is one of the important factors that retains high reactivity of 1-hexene and encourages high comonomer incorporation. As compared with the works done by our group previously with normal metallocene, it has been found that with the same initial comonomer concentration in copolymerization, the obtained copolymer from those studies exhibited much lower comonomer incorporation than in this study $[14,15]$.

On account of the fact that the uniform comonomer incorporation is the key feature for producing lowdensity plastomer, which exhibited plastic and elas-

Table 2. Comonomer incorporation and the reactivity ratios

\begin{tabular}{|c|c|c|c|c|c|c|c|}
\hline \multirow{2}{*}{ Entry } & \multirow{2}{*}{$\begin{array}{c}\text { Ethylene } \\
{[\mathbf{m o l} / \mathbf{l}]}\end{array}$} & \multirow{1}{*}{$\begin{array}{c}\text { 1-Hexene } \\
{[\mathbf{m o l} / \mathbf{l}]}\end{array}$} & \multicolumn{2}{|c|}{ Incorporation $^{\mathbf{a}}$} & \multicolumn{3}{|c|}{ Reactivity $^{\mathbf{b}}$} \\
\cline { 4 - 9 } & & $\mathbf{E}[\mathbf{m o l} \mathbf{\%}]$ & $\mathbf{H}[\mathbf{m o l} \mathbf{\%}]$ & $\mathbf{r}_{\mathbf{E}}$ & $\mathbf{r}_{\mathbf{H}}$ & $\mathbf{r}_{\mathbf{E}} \mathbf{r}_{\mathbf{H}}$ \\
\hline 3 & 0.6 & 0.3 & 68.4 & 31.6 & 1.121 & 0.658 & 0.737 \\
\hline 4 & 0.6 & 0.6 & 43.7 & 56.3 & 0.797 & 0.738 & 0.588 \\
\hline 5 & 0.6 & 1.2 & 23.0 & 77.0 & 0.621 & 0.784 & 0.487 \\
\hline
\end{tabular}

aExamined by ${ }^{13} \mathrm{C}-\mathrm{NMR}$ by Randall method [8]

bRelative comonomer reactivities ( $r_{E}$ for ethylene and $\mathrm{r}_{H}$ for 1-hexene) calculated by $r_{E}=2[\mathrm{EE}] /[\mathrm{EC}] \mathrm{X}, r_{H}=2 \mathrm{X}[\mathrm{CC}] /[\mathrm{EC}]$, $[\mathrm{EE}]=[\mathrm{EEE}]+0.5[\mathrm{CEE}],[\mathrm{CC}]=[\mathrm{CCC}]+0.5[\mathrm{ECC}],[\mathrm{EC}]=[\mathrm{CEC}]+0.5[\mathrm{CEE}]+[\mathrm{ECE}]+0.5[\mathrm{ECC}]$ 
Table 3. Triad distribution of copolymer obtained from ${ }^{13} \mathrm{C}-\mathrm{NMR}$

\begin{tabular}{|c|c|c|c|c|c|c|c|c|}
\hline Entry & $\begin{array}{c}\text { Ethylene } \\
{[\mathbf{m o l} / \mathbf{l}]}\end{array}$ & $\begin{array}{c}\text { 1-Hexene } \\
{[\mathbf{m o l} / \mathbf{l}]}\end{array}$ & EEE & EEH & HEH & EHE & EHH & HHH \\
\hline 3 & 0.6 & 0.3 & 0.345 & 0.292 & 0.048 & 0.172 & 0.144 & 0.000 \\
\hline 4 & 0.6 & 0.6 & 0.091 & 0.270 & 0.076 & 0.185 & 0.339 & 0.039 \\
\hline 5 & 0.6 & 1.2 & 0.015 & 0.130 & 0.085 & 0.154 & 0.424 & 0.192 \\
\hline
\end{tabular}

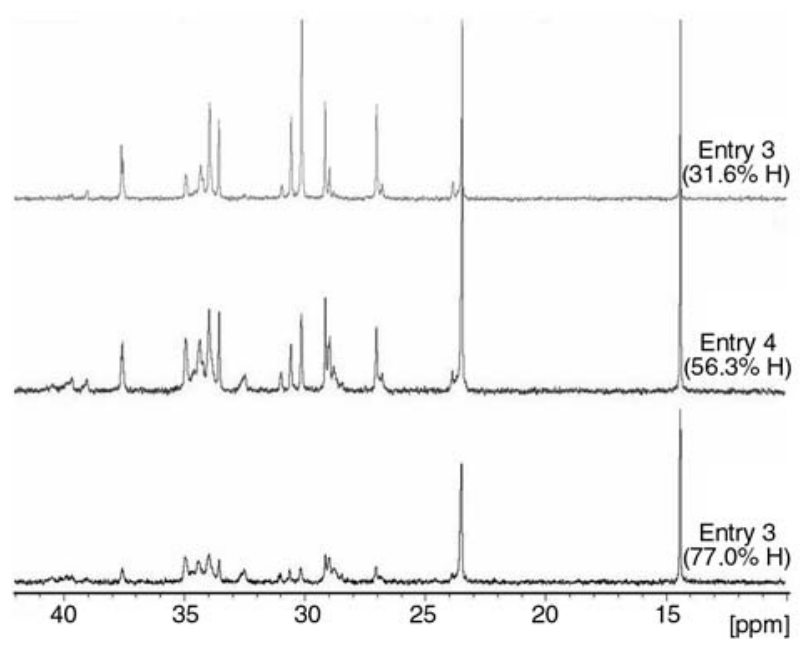

Figure 3. ${ }^{13} \mathrm{C}-\mathrm{NMR}$ spectra of copolymers

tomeric behavior [16], the distribution of comonomer in the copolymers needs to be concerned in order to obtain plastomers with desired specification. The triad distribution for all copolymers obtained from ${ }^{13} \mathrm{C}-\mathrm{NMR}$ is shown in Table 3 . Triad block of comonomer (HHH) was detected in samples having 1-hexene incorporation above $31.6 \%$ (entry 4, 5). It was also noticed from Figure 3, which showed ${ }^{13} \mathrm{C}-\mathrm{NMR}$ spectrum of the copolymers that the peaks between 39.5 and 42 ppm (proportional to the HHH triad) occurred obviously in the copolymer from entry $\mathbf{4}$ and $\mathbf{5}$. Nevertheless, the number of $\mathrm{HHH}$ triad was not converted directly from the area under these peaks. There are other peaks, which are more pronounced in the calculation. Therefore, the larger area of these peaks of entry 4 than entry 5 did not mean that entry 4 had more HHH triad than entry 5.

The presence of $\mathrm{HHH}$ triad can imply that the good distribution of comonomer throughout the copolymer chain was interrupted at high incorporation of comonomer. Although the copolymers with high 1-hexene incorporation contain the block of comonomer, they are still not the block copolymer. It can be observed from the product of reactivity ratio $\left(r_{E} r_{H}\right)$, which is one of the parameters that can identify types of copolymer. A value $r_{E} r_{H}>1$ indicates a block copolymer structure and $r_{E} r_{H}<1$ reveals an alternating copolymer structure. Therefore, all the obtained copolymers are alternating copolymers having the $r_{E} r_{H}$ value being lower than 1 . Once the alternating copolymers were obtained, it means the comonomers in their chain are distributed moderately well along the backbone, then shortening the average backbone sequence length for crystallization and therefore low crystallinity, including low density, would be gained. Thus, with these properties, the obtained copolymers are in closing proximately to be low-density plastomer. However, these copolymers might not meet all properties required for the use in plastic industry because they probably lost completely the thermal properties.

As a result of the fact that disadvantages of alternating copolymer, which have been found by Hung et al. [17] that the polymer with a highly alternating sequence distribution did not exhibit any melting behavior. Based on the result, when the incorporations of comonomers increased, the obtained polymer tended to exhibit more highly alternating copolymer structure $\left(r_{E} r_{H}<1\right)$. Therefore, they might lose the melting behavior at high level of 1-hexene incorporation. To prove that, melting temperatures of the obtained polymers were investigated by differential scanning calorimetry (DSC). From the investigation, it was found that only the sample from entry 2, which is the polyethylene sample, has the melting temperature $\left(130^{\circ} \mathrm{C}\right)$ and the remaining samples cannot be found the melting temperatures. Thus, the losses of thermal properties existed in all obtained copolymers even the one that had low comonomer content (entry 3, 31.6\%).

Copolymers were formed the gel-like structure as seen in Figure 4 when the 1-hexene was introduced into the system, especially at the high level of incorporation. With this structure, it is obviously shown the character of amorphous material. Therefore, it accords with the results from ${ }^{13} \mathrm{C}-\mathrm{NMR}$ and DSC that the obtained copolymers should not have the melting temperature. 


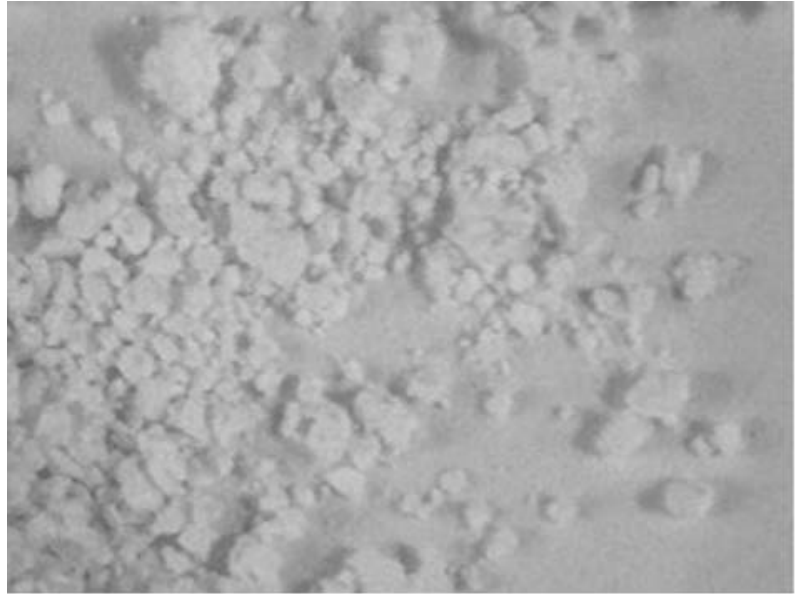

a)

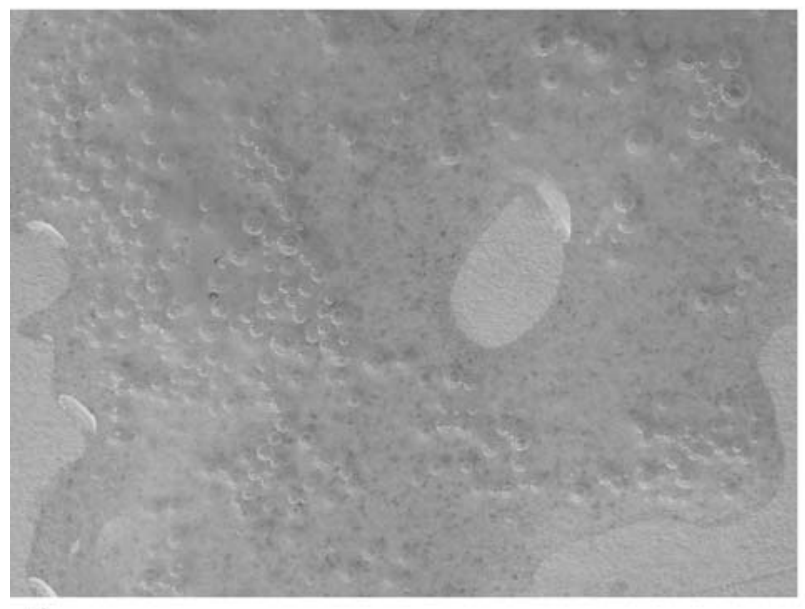

c)

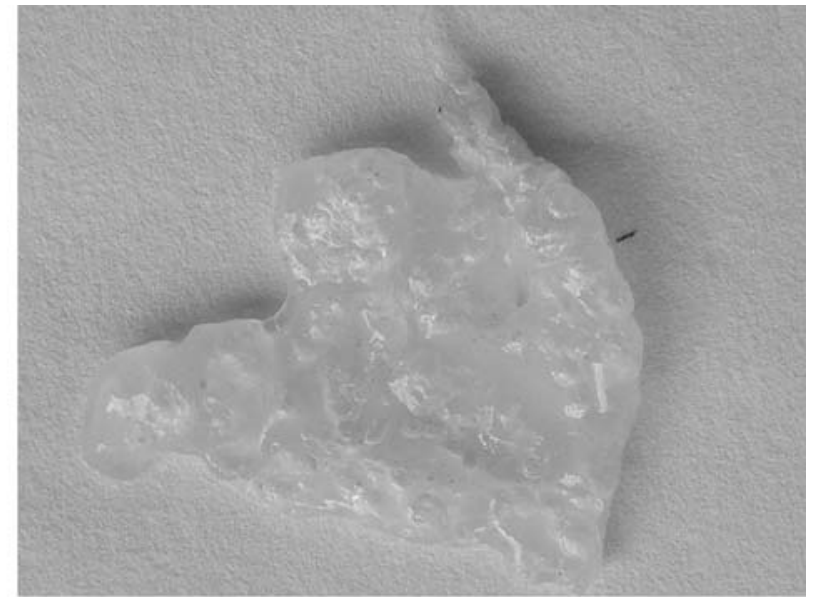

b)

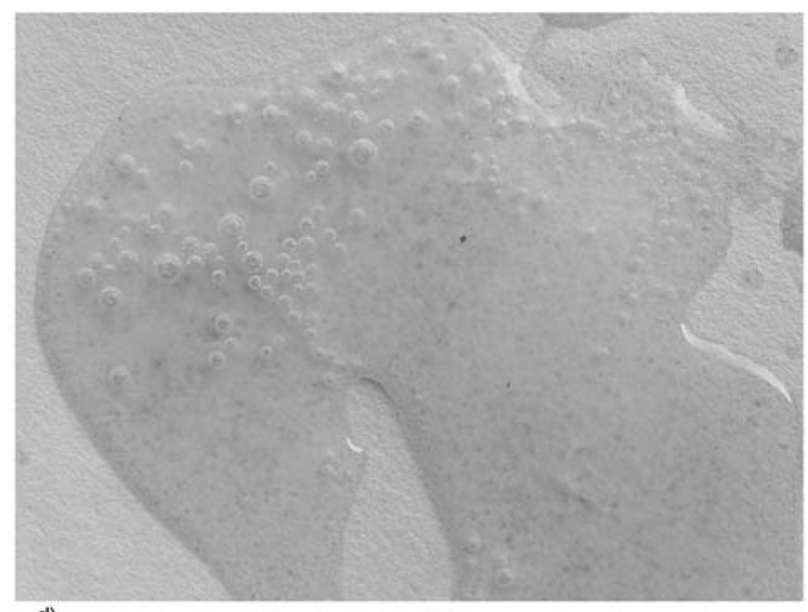

d)

Figure 4. Digital photograph of copolymer with various 1-hexene contents a) $0 \%$, b) $31.6 \%$, c) $56.3 \%$ and d) $77.0 \%$

\section{Conclusions}

It was found that the positive comonomer effect occurred even though a very high concentration of 1-hexene that was introduced into the system. However, the microstructures of the obtained copolymer examined by ${ }^{13} \mathrm{C}-\mathrm{NMR}$ need to be improved because the highly alternating sequence distributions of copolymer cause the loss of essential specific thermal properties.

\section{Acknowledgements}

We thank the Thailand Research Fund (TRF), the Commission of Higher Education (CHE) of Thailand and PTT Research and Technology Institute for the financial support of this project.

\section{References}

[1] Speed C. S., Trudell B. C., Mehta A. K., Stehling F. C.: Structure/property relationships in EXPOL ${ }^{\mathrm{TM}}$ polymers. in 'Society of plastics engineers polyolefins, VII International conference, Houston, Texas' 45-66 (1991).

[2] Jongsomjit B., Chaichana E., Praserthdam P.: LLDPE/ nano-silica composites synthesized via in situ polymerization of ethylene/1-hexene with $\mathrm{MAO} / \mathrm{metal}$ locene catalyst. Journal of Material Science, 40, 2043 2045 (2005). DOI: $10.1007 / \mathrm{s} 10853-005-1229-\mathrm{Z}$

[3] Hong H., Zhang Z., Chung T. C. M., Lee R. W.: Synthesis of new 1-decene-based LLDPE resins and comparison with the corresponding 1-octene- and 1-hexene-based LLDPE resins. Journal of Polymer Science Part A: Polymer Chemistry, 45, 639-649 (2007). DOI: $10.1002 /$ pola.21825

[4] Kaminsky W., Tran P-D., Weingarten U.: New materials by polymerisation of olefins and styrene with metallocene catalysts. Macromolecular Symposia, 193, 1-11 (2003).

DOI: $10.1002 /$ masy. 200390053 
[5] van Grieken R., Carrero A., Suarez I., Paredes B.: Effect of 1-hexene comonomer on polyethylene particle growth and kinetic profiles. Macromolecular Symposia, 259, 243-252 (2007).

DOI: $\underline{10.1002 / \text { masy. } 200751329}$

[6] Galland G. B., Seferin M., Mauler R. S., Dos Santos J. H. Z.: Linear low-density polyethylene synthesis promoted by homogeneous and supported catalysts. Polymer International, 48, 660-664 (1999).

DOI: 10.1002/(SICI)1097-0126(199908)48:8<660:: AID-PI212>3.0.CO;2-L

[7] Hagihara H., Shiono T., Ikeda T.: Living polymerization of propene and 1-hexene with the $\left[t\right.$-BuNSiMe ${ }_{2}$ Flu $] \mathrm{TiMe}_{2} / \mathrm{B}\left(\mathrm{C}_{6} \mathrm{~F}_{5}\right)_{3}$ catalyst. Macromolecules, 31, 3184-3188 (1998).

DOI: $10.1021 / \mathrm{ma} 971697 \mathrm{k}$

[8] Randall J. C.: A review of high resolution liquid 13 carbon nuclear magnetic resonance characterizations of ethylene-based polymers. Polymer Reviews, 29, 201-317 (1989).

DOI: $10.1080 / 07366578908055172$

[9] Intaragamjon N., Shiono T., Jongsomjit B., Praserthdam P.: Elucidation of solvent effects on the catalytic behaviors for $\left[t\right.$-BuNSiMe ${ }_{2}$ Flu $] \mathrm{TiMe}_{2}$ complex during ethylene/1-hexene copolymerization. Catalysis Communications, 7, 721-727 (2006).

DOI: $10.1016 /$ j.catcom.2006.02.022

[10] Severn J. R., Chadwick J. C.: Tailor-made polymers: Via immobilization of alpha-olefin polymerization catalysts. Wiley-VCH, Weinheim (2008).

[11] Kawahara N., Saito J., Matsuo S., Kaneko H., Matsugi T., Toda Y., Kashiwa N.: Study on unsaturated structures of polyhexene, poly(4-methylpentene) and poly(3-methylpentene) prepared with metallocene catalysts. Polymer, 48, 425-428 (2007).

DOI: $10.1016 /$ j.polymer.2006.11.001
[12] Krenstel B. A., Kissin Y. V., Kleiner V. J., Stotskaya L. L.: Polymer and copolymer of higher $\alpha$-olefins. Hanser Publishers, Munich (1997).

[13] Forlini F., Fan Z-Q., Tritto I., Locatelli P., Sacchi M. C.: Metallocene-catalyzed propene/1-hexene copolymerization: Influence of amount and bulkiness of cocatalyst and of solvent polarity. Macromolecular Chemistry and Physics, 198, 2397-2408 (1997). DOI: $10.1002 / \mathrm{macp} .1997 .021980804$

[14] Jongsomjit B., Ngamposri S., Praserthdam P.: Application of silica/titania mixed oxide supported zirconocene catalyst for synthesis of linear low-density polyethylene. Industrial and Engineering Chemistry Research, 44, 9059-9063 (2005).

DOI: $10.1021 / \mathrm{ie} 050806 \mathrm{~d}$

[15] Bunchongturakarn S., Jongsomjit B., Praserthdam P.: Impact of bimodal pore MCM-41-supported zirconocene/dMMAO catalyst on copolymerization of ethylene/1-octene. Catalysis Communications, 9, 789-795 (2008).

DOI: $\underline{10.1016 / \text { j.catcom.2007.09.001 }}$

[16] Yu T. C.: Metallocene plastomer modification of polypropylenes. Polymer Engineering and Science, 41, 656-671 (2001). DOI: $10.1002 /$ pen. 10761

[17] Hung J., Cole A. P., Waymouth R. M.: Control of sequence distribution of ethylene copolymers: Influence of comonomer sequence on the melting behavior of ethylene copolymers. Macromolecules, 36, 24542463 (2003).

DOI: $\underline{10.1021 / \mathrm{ma} 021779 \mathrm{y}}$ 